19 Revue d'histoire du XIXe siècle

Société d'histoire de la révolution de 1848 et des

révolutions du XIXe siècle

$1 \mid 1985$

Varia

\title{
Le mot du président ou les raisons et les limites d'un retour aux sources
}

Philippe Vigier

\section{OpenEdition}

Journals

Édition électronique

URL : http://journals.openedition.org/rh19/1

DOI : $10.4000 /$ rh 19.1

ISSN : $1777-5329$

Éditeur

La Société de 1848

Édition imprimée

Date de publication : 1 juin 1985

ISSN : 1265-1354

Référence électronique

Philippe Vigier, « Le mot du président ou les raisons et les limites d'un retour aux sources », Revue d'histoire du XIXe siècle [En ligne], 1 | 1985, mis en ligne le 28 octobre 2002, consulté le 22 septembre 2020. URL : http://journals.openedition.org/rh19/1 ; DOI : https://doi.org/10.4000/rh19.1

Ce document a été généré automatiquement le 22 septembre 2020

Tous droits réservés 


\title{
Le mot du président ou les raisons et les limites d'un retour aux sources
}

\author{
Philippe Vigier
}

Il y a deux ans déjà que la Société d'histoire de la révolution de 1848 et des révolutions du XIXe siècle a admis le principe de renouer avec une tradition de publication périodique qui lui soit propre. Une tradition qui remontait à ses origines même --en 1904-- mais qui, après bien des avatars, s'était interrompue depuis le début des années 1950.

Ce qui ne veut pas dire que, depuis lors, la Société ait cessé toute activité. Tant s'en faut. En dehors d'assemblées générales annuelles, en février, bien sûr, qui permettaient d'entendre d'intéressantes communications scientifiques, elle a publié, avec une périodicité malheureusement irrégulière, des volumes d'Études groupées autour d'un thème : Armée, Choléra, Crise de 1846-1851, Presse ouvrière. Impossible prison, Utopismes sociaux, etc. Enfin, depuis une dizaine d'années, grâce essentiellement à Maurice Agulhon qui m'a précédé à la tête d'une société à laquelle il a donné une nouvelle vie, successivement Les Annales historiques de la Révolution française, puis Romantisme, ont accepté (et nous en sommes fort reconnaissants aux responsables de ces revues) d'insérer dans leurs publications propres une chronique réservée à notre société.

Nous voici revenus à la solution d'un périodique annuel accueillant articles de fond, comptes rendus, chroniques, etc. émanant des membres de notre société --de jeunes chercheurs, en particulier-- auxquels nous souhaitons largement ouvrir cette tribune. C'est que l'expérience a prouvé qu'il est bien difficile à une Société savante de conserver ses adhérents, et surtout (ce qui est notre ambition) d'en recruter de nouveaux, sans le support d'une publication régulière et autonome. Même si celle-ci se veut modeste --dans la mesure, en particulier, où la Société entend également publier, tous les deux ans, les Actes du colloque où sont présentés les résultats du thème de recherche autour duquel nous entendons, davantage que précédemment, mobiliser le maximum de sociétaires, tout en élargissant notre "champ de recrutement", aux non- 
historiens tout particulièrement. Fort encourageante, à cet égard, me semble l'expérience faite, les deux dernières années, autour du thème du Maintien de l'ordre au XIX siècle : le colloque conclusif, tenu en décembre 1983, a connu un si franc succès que nous avons décidé de prolonger, et d'élargir notre enquête, en traitant, dans les deux années qui viennent, des victimes du maintien de l'ordre, et de la prison politique. Encore faut-il, bien sûr, que publication annuelle et recherche collective répondent à un besoin ressenti par un nombre suffisant de chercheurs et lecteurs professionnels ou bénévoles. Y a-t-il place. actuellement, pour une société qui se donne pour tâche d'étudier les grandes mutations survenues au XIX ${ }^{e}$ siècle dans la France et dans le monde, ainsi que les problèmes qu'elles posent, et les résistances qu'elles suscitent -ceci tout en respectant le désir des fondateurs d'attacher une particulière importance au phénomène révolutionnaire, et aux réactions qu'il provoque?

C'est parce que nous le pensons que nous continuons l'entreprise sur ces bases élargies. Avec la ferme volonté d'approfondir, et de mieux faire connaître, le renouvellement intervenu depuis plusieurs décennies dans cette histoire du siècle passé dont la richesse foisonnante est encore (contrairement à ce que l'on pense souvent...) insuffisamment connue. L'apport des littéraires, des sociologues, des politologues, des philosophes... a été essentiel dans l'élargissement d'un champ historique qui couvre les phénomènes culturels et artistiques, les faits de mentalités, aussi bien que le social et le politique, largement renouvelés par ailleurs ; aussi comptons-nous beaucoup sur leur concours, comme sur ceux de nos collègues étrangers, qui ont tant contribué, ces derniers temps, à une meilleure connaissance du XIX ${ }^{e}$ siècle français --pour ne parler que de lui. Possible, l'entreprise nous apparaît également nécessaire --dans la mesure où, dans notre pays du moins, existe actuellement un étonnant décalage (mais n'est-il pas révélateur de crise ?) entre l'intérêt passionné que l'histoire du XIX ${ }^{\mathrm{e}}$ siècle suscite dans un très vaste public, et la place réduite qui lui est faite, depuis quelques années, dans les programmes scolaires. Les Commissions Girault, puis Le Goff, de réforme et de revalorisation de l'enseignement de l'Histoire, l'ont d'ailleurs déploré, et comptent bien "corriger le tir". Nous souhaitons nous associer à cet effort de remise en perspective -convaincus que nous sommes du rôle essentiel joué par les faits, les œuvres et les hommes du siècle passé dans la formation et, partant, dans la compréhension du monde contemporain.

Un dernier mot : ce bulletin n'aurait pas vu le jour sans la foi et l'efficacité de JeanClaude Caron qui, au sein de notre bureau, en a accepté la responsabilité rédactionnelle. Qu'il en soit vivement remercié. 